\title{
Role of proactive interference in infantile forgetting
}

\author{
GREGORY J. SMITH \\ Case Western Reserve University, Cleveland, Ohio 44I06 \\ and \\ NORMAN E. SPEAR \\ State University of New York, Binghamton, New York 13901
}

\begin{abstract}
Ontogenetic changes in the role of proactive interference in augmenting forgetting were tested with 444 rats as subjects. In Experiment 1, Phase 1 (the source of proactive interference) included events that were contingent or not contingent on responding in the context of either the Phase 2 training apparatus or a distinctly different apparatus. After learning a spatial discrimination for Phase 2, retention tests were given after intervals of 2 min, 1 day, 7 days, 30 days, or 65 days. The results indicated: (1) infantile amnesia, and (2) proactive interference for infant rats but not for adults, in spite of substantial simple forgetting among adults. Experiment 2 extended the test to a go/no-go avoidance task. The results of Experiment 2 gave some indication that infants were more susceptible than were adults to proactive interference over short intervals, but the generality of this relationship was sufficiently ambiguous as to suggest different mechanisms of interference for the discrimination and go/no-go tasks. These data indicate multiple mechanisms of infantile forgetting that may vary with certain characteristics of the task.
\end{abstract}

Theories of infantile amnesia have typically assumed that the mechanisms for exaggerating the rate of forgetting observed during infancy are inoperable in the mature adult (Allport, 1937; Freud, 1935; Perkins, 1965; Reiff \& Scheerer, 1959). One compelling set of experiments that specifically addressed this issue was reported by Campbell, Misanin, White, and Lytle (1974). These authors hypothesized that the fast rate of forgetting characterizing infancy was a result of the rapid maturational development of the central nervous system (CNS) that occurs at this time. To test this notion, Campbell et al. (1974) examined the long-term retention of infant and adult animals across two species, the rat (altricial) and the guinea pig (precocial). To the extent that development of the CNS is the primary determinant of infantile forgetting, retention differences between immature and mature rats should be greater than those between immature and mature guinea pigs. The results of that study showed that, while immature rats forgot very rapidly relative to mature rats over a 1-2-week retention interval, immature and mature guinea pigs exhibited equivalent retention after inter-

Preparation of this manuscript was supported by grants from the National Science Foundation (BNS 74-24194 and BNS $78-02360$ ) to the second author. The assistance of Norman G. Richter and Teri Tanenhaus is gratefully acknowledged. Requests for reprints should be sent to Norman E. Spear, Department of Psychology, State University of New York, Binghamton, New York 13901 . vals as long as 10-11 weeks. These data were taken by Campbell and his associates as support for the physiological maturational hypothesis, an indication that CNS development contributes significantly to exacerbating forgetting during infancy.

An alternative approach to infantile amnesia is the idea that immature animals are merely more susceptible to the same sources of forgetting that affect the adult (e.g., proactive and retroactive interference). Tests of this approach have suggested that retroactive interference may be more pronounced in infant than in adult organisms (Smith, 1968; Berk, Vigorito, \& Miller, Note 1). Proactive interference, on the other hand, has been discounted as a major component of infantile forgetting on logical grounds (Campbell \& Coulter, 1976). This argument, however, fails to consider the likelihood of greater proactive interference from events more temporally contiguous to the episode to be remembered.

According to the simplest model of proactive interference (PI), PI should be greater in the mature organism than in the infant since the adult brings to the experimental setting a greater number of extraexperimental sources of interference than does the infant. However, if the interfering properties of acquired events are exacerbated in the immature organism, as suggested by the effects of retroactive interference on infantile forgetting, then PI might also be expected to play an important role in the enhanced forgetting of infancy. Only a few pertinent 
studies have appeared in the literature to date. For example, data by Kail and Schroll (1974) suggest that young children (7-year-olds) are affected more by PI than are older children (11-year-olds), although a firm conclusion is precluded because the degree of original learning and word list difficulty were inadequately controlled. Spear, Gordon, and Chiszar (1972) reported that prior passive-shock-avoidance training increased the rate of forgetting of a subsequently acquired active-shock-avoidance memory in both adult and weanling (23-26-day-old) rats. The results indicated some tendency for PI to be more pronounced for the weanlings than for the adults, but this inference was not supported statistically. Moreover, the youngest animals in the Spear et al. study were beyond the age of substantial infantile amnesia, and only a single source of proactive interference was considered. The present experiments were designed to examine in a systematic manner the effect of a variety of potential sources of PI on the forgetting observed among immature rats, relative to that found for adults.

In Experiment 1, rats (16 days old vs. adults) were exposed to one of five proactive interference treatments prior to learning a spatial discrimination to escape from footshock. Retention of spatial discrimination was measured $2 \mathrm{~min}, 1$ day, or 7 days following training in Part $A$ of Experiment 1 and 1 day, 30 days, or 65 days following training in Part B of Experiment 1 . Experiment 2 attempted to extend the findings of Experiment 1 by using a go/no-go avoidance task to assess the role of PI in infantile forgetting.

\section{EXPERIMENT 1}

\section{Method}

\section{Subjects}

The subjects in Part A of Experiment 1 were 300 albino rats derived from the Sprague-Dawley strain, born and reared in the colony at the State University of New York at Binghamton. These rats were assigned to two age groups: 150 16-day-old rat pups (infants) chosen from 20 litters, and 150 80-110-day-old rats (adults). Within each of the two age groups, these rats were assigned randomly to one of five treatment conditions ( 30 per group), with the constraint that an equal number of males and females be in each group. Part $B$ used 48 rats, $80-110$ days of age, having the same description as those in Experiment $A$. These rats were assigned randomly, 24 per group, to one of two treatment conditions, with 12 males and 12 females per group.

\section{Housing}

All rats were housed in litters culled to 10-12 pups, with their parents and littermates, until weaning at 21 days postnatally. At weaning, all rats were separated according to sex and housed in polypropylene group cages until approximately 26 days of age. At this point, all rats were moved to steel mesh laboratory gang cages until training or testing. At all times, rats were maintained with ad-lib food (Purina Rat Chow) and water in a climatecontrolled vivarium on an 0700 (lights on) to 2300 (lights off) cycle. Training and testing occurred between 0800 and $1600 \mathrm{~h}$.

\section{Apparatus}

Two T-mazes, scaled to the size of infant and adult rats, were used in the experiment. The infant T-maze (stem, $19 \mathrm{~cm}$ long $x$ $8 \mathrm{~cm}$ wide $\times 9 \mathrm{~cm}$ high; each arm, $10 \mathrm{~cm}$ long $\times 8 \mathrm{~cm}$ wide $\times 9 \mathrm{~cm}$ high) and adult $T$-maze (stem, $36 \mathrm{~cm}$ long $\times 11 \mathrm{~cm}$ wide $\times 12 \mathrm{~cm}$ high; each arm, $39 \mathrm{~cm}$ long $\times 16 \mathrm{~cm}$ wide $\times 12 \mathrm{~cm}$ high) were both made from clear Plexiglas and were mounted on grid floors that could be electrified $(.8 \mathrm{~mA})$ by a Lehigh Valley Electronics shock generator and scrambler (Model 26861) with power supplied by a Scientific Prototype transformer (Model 4026J). The startbox of both mazes was lined with black construction paper and separated from the choice point by a Plexiglas guillotine door and illuminated from beneath the grid floor by two 6-W incandescent light bulbs. The latency to make a choice was recorded by a running time meter, which was initiated with the shock and was terminated by the experimenter when the animal placed four paws in the appropriate arm of the maze.

A Plexiglas box (adults: $30 \mathrm{~cm}$ long $\times 30 \mathrm{~cm}$ wide $\times 64 \mathrm{~cm}$ high; infants: $10 \mathrm{~cm}$ long $\times 7.5 \mathrm{~cm}$ wide $\times 9 \mathrm{~cm}$ high) was used to ad. minister noncontingent footshocks to rats. The apparatuses were equipped with a grid floor identical to that found in the T-mazes and could be attached to the same shock source.

\section{Procedure}

Pretreatment. Twenty-four hours prior to the start of the experiment, all rats were handled, identified, and assigned randomly to groups.

Phase 1 experience. At this point in training, all infants were 16 days of age, and all adults were 80-110 days of age. Treatment started by hand-carrying each rat from its homecage to a dimly lit experimental room and placing it in a wire-mesh holding cage for 30-sec prior to the beginning of the treatment.

Group $\mathrm{C}^{\prime} / \mathrm{C}$ was trained to approach a randomly predetermined correct choice (left or right) to escape the footshock. Training consisted of 12 trials per day, using a correction training procedure until the rat reached the training criterion of 9 correct choices in any 10 consecutive trials.

Group $\mathrm{R} / \mathrm{C}$ was exposed to the training apparatus for the same number of training trials as a matched agemate in $C^{\prime} / C$. The correct arm to escape the footshock was predetermined randomly for each trial by a computer-generated table of sequence events (Vandament, Burright, Fessenden, \& Barker, 1970). Unlike $C^{\prime} / C$, no consistent cues were available to the rat for predicting the correct choice. However, similar to $\mathrm{C}^{\prime} / \mathrm{C}$, this group experienced the instrumental running contingencies associated with shock termination (i.e., the rat eventually did escape shock by running into the correct arm).

Group $\mathrm{Y} / \mathrm{C}$ was treated identically to $\mathrm{R} / \mathrm{C}$ except that no aspect of the rat's responding (i.e., neither choice nor running) led to escape from shock in a predictable fashion. This was accomplished by exposing the rat to the T-maze (with all doors of the maze open to allow unrestricted access to all arms of the maze) for the same number of trials as $C^{\prime} / C$ and $R / C$, but because duration of shock on each trial was equated with that of a yoked/ matched age-mate in $R / C$, the shock terminated regarcless of where in the maze the $\mathrm{Y} / \mathrm{C}$ rat was and what it was doing.

Group NC/C was treated identically to $Y / C$ except that the footshock was administered in a quite different (cube-shaped) apparatus located in the experimental room. This group was included to assess the effect of noncontingent shock presentations outside the training context on later learning and retention of a spatial discrimination.

Upon completion of each trial, each rat was removed from the apparatus and was placed in a steel-mesh holding cage for an intertrial interval (ITI) of $30 \mathrm{sec}$. Each rat in Groups R/C, Y/C, and $\mathrm{NC} / \mathrm{C}$ was given a maximum of 12 trials a day until a matched age-mate of Group $C^{\prime} / C$ reached the training criterion of 9 correct choices in any 10 consecutive trials.

Phase 2 training. Twenty-four hours after the completion of Phase 1 experience, all rats were trained to choose the nonpreferred arm of the T-maze to escape the footshock. The mean age of the infants at the start of Phase 2 training was 17.8 days. For $C^{\prime} / C$, the rat was required to choose the arm opposite to that chosen during Phase 1 experience (i.e., reversal learning). 
For Groups $\mathrm{R} / \mathrm{C}, \mathrm{Y} / \mathrm{C}$, and $\mathrm{NC} / \mathrm{C}$, rats were required to choose the arm opposite to that chosen on the first trial of Phase 2 learning. In addition, at this point, a fifth group $(-/ C)$ was added-experimentally naive age-mates. Note that $-/ C$ was made up of age-matched littermates in both age groups. As with other groups, $-/ \mathrm{C}$ was trained against its first trial preference. As in Phase 1 , training consisted of 12 trials per day $($ ITI $=30 \mathrm{sec})$ until the Phase 2 training criterion ( 8 correct choices in any 10 consecutive trials) was reached. Upon completing the Phase 2 training criterion, each rat was assigned in a random block fashion to one of the retention intervals. Each group comprised an equal number of males and females.

Testing. Testing in Experiment $1 \mathrm{~A}$ occurred $2 \mathrm{~min}, 1$ day, or 7 days after Phase 2 learning. Testing in Experiment 1B occurred either 1 day, 30 days, or 65 days after Phase 2. Testing consisted of 10 shock-escape trials in the same apparatus used for training. Similar to training, all rats were placed in the startbox of the maze facing away from the guillotine door. Upon raising the door, a .8-mA footshock was delivered through the grid floor. To escape the shock, the rat was required to make a choice. Unlike training, a choice of either arm of the maze terminated the footshock.

Design. The overall design of Experiment $1 \mathrm{~A}$ was a $2 \times 5 \times 3$ factorial $[2$ age groups (infants and adults) $\times 5$ treatment conditions $\left(C^{\prime} / \mathrm{C}, \mathrm{R} / \mathrm{C}, \mathrm{Y} / \mathrm{C}, \mathrm{NC} / \mathrm{C},-/ \mathrm{C}\right) \times 3$ retention intervals ( $2 \mathrm{~min}, 1$ day, 7 days)]. There were 30 orthogonal groups made up of 5 males and 5 females each.

The design of Experiment $1 \mathrm{~B}$ was a $2 \times 3$ factorial using only adult rats $\left[2\right.$ treatment conditions $\left(C^{\prime} / C\right.$ and $-/ C$ ) and 3 retention intervals ( 1 day, 30 days, and 65 days)]. There was a total of 6 independent groups, each comprised of 4 males and 4 females. From both parts of the experiments, a number of response measures were obtained from each rat and were analyzed by parametric analysis of variance tests using the appropriate planned and post hoc comparisons to ascertain the nature of the statistical interactions and main effects (Keppel, 1973).

\section{Results}

\section{Acquisition, Phase 1}

Analyses of trials to complete criterion and trial of last error were performed on data collected in Experiments $1 \mathrm{~A}$ and 1B. In Experiment $1 \mathrm{~A}$, a $2 \times 3 \times 2$ factorial analysis (2 ages $\times 3$ retention intervals $\times$ male vs. female subjects) on rate of criterion completion for Group $C^{\prime} / C$ indicated that 16-day-old rats, requiring on the average 20.1 training trials to complete the criterion, were slower to acquire the spatial discrimination than were adult rats, whose mean was $12.8[\mathrm{~F}(1,48)=15.57, \mathrm{p}<.001]$. The analysis also indicated an age $\times$ sex interaction $[F(1,48)$ $=4.22, p<.05]$ with more rapid learning by females than by males among infants but not adults, but since the sex variable failed to affect subsequent retention behavior, no further mention will be made of it. No other interactions or main effects approached statistical significance (all ps $>.25$ ). A closer analysis of behavior during the criterion run indicated that, in terms of errors committed once the first correct choice of the criterion run was made, $53 \%$ of the infants as compared with $37 \%$ of the adults made errors $\left(\chi^{2}=3.81, \mathrm{p}<.06\right)$. This was further indicative of the overall slower rate of learning among infant rats. This response measure becomes especially important for assessing rate of learning differences between groups and across ages when the criterion level allows, as in the present experiment, for an error to occur during the criterion run.

For Experiment $1 \mathrm{~B}$, a $3 \times 2$ analysis of variance (3 retention intervals $\times$ male vs. female rats) on trials to complete criterion training indicated no significant differences among adult treatment conditions (all ps $>.10$ ). In agreement with Experiment 1A, only $29 \%$ of the adults made at least one error after the first correct choice of the criterion run.

\section{Acquisition, Phase 2}

Twenty-four hours after completion of Phase 1 training, all rats were hand-carried to the experimental room for Phase 2 training. Phase 2 involved training these rats to a less stringent training criterion than that used during Phase 1 ( 8 correct choices in any 10 consecutive trials). This change in criterion was prompted by evidence suggesting that proactive interference may be increased in subjects receiving training to a higher criterion on Phase 1 than on the critical task (Spear et al., 1972; Underwood \& Ekstrand, 1966).

For Experiment $1 \mathrm{~A}$, a $2 \times 3 \times 5 \times 2$ analysis ( 2 ages $\times 3$ retention intervals $\times 5$ treatment conditions $X$ male vs. female rats) of the data representing number of trials to complete criterion training failed to indicate higher order interactions or main effects involving the factor of sex or subsequent retention interval, so henceforth Phase 2 scores are pooled across these factors. This analysis did indicate the presence of a main effect of age $[F(1,240)=7.21$, $p<.01]$ and treatment conditions $[F(4,240)=10.72$, $\mathrm{p}<.001]$. The interaction between age and treatment conditions, however, was not significant $[F(4,240)=$ $2.07, \mathrm{p}<.10]$. No other main effects or interactions approached statistical significance (see Figure 1).

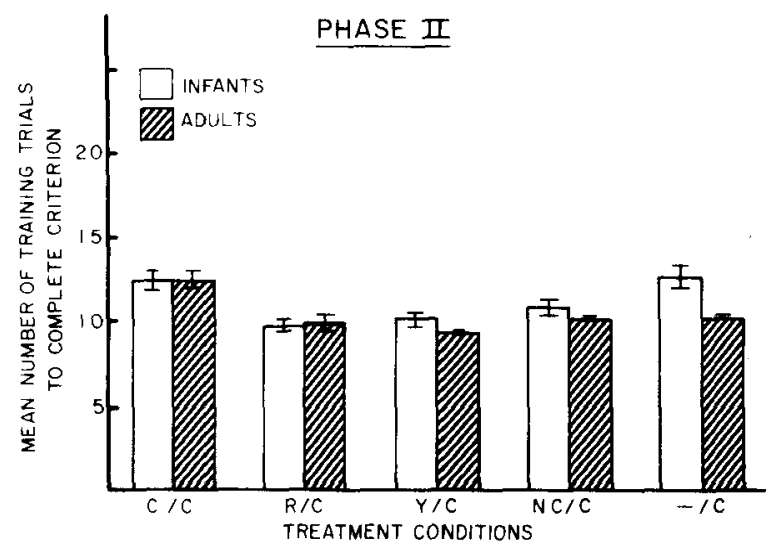

Figure 1. Phase 2 acquisition: mean number of training trials to complete training (8 correct choices in any 10 consecutive trials given on a day). 
Using the Dunn test to control for the experimentwise error rate, comparisons were performed between specific treatment conditions (Keppel, 1973). Relative to age-mates in the control treatment $(-/ \mathrm{C})$, infants in Groups $\mathrm{R} / \mathrm{C}$ and $\mathrm{Y} / \mathrm{C}$ exhibited positive transfer of learning from Phase 1 to Phase 2 (both ps $<.05)$. This positive transfer of learning was apparently the result of prior experience with the training apparatus, since Group $\mathrm{NC} / \mathrm{C}$, receiving the same Phase 1 noncontingent footshocks in a different apparatus, failed to differ from Group -/C. Note, also, that Group C'/C's failure to exhibit negative transfer relative to the control treatment may be taken as additional support that prior cue exposure in this case tended to facilitate subsequent learning.

Adult rats showed little effect of Phase 1 experience on acquisition during Phase 2 . The only exception was that Group $\mathrm{C}^{\prime} / \mathrm{C}$ demonstrated reliable negative transfer relative to the control treatment, Group -/C $(\mathrm{p}<.05)$.

Comparisons performed across ages indicated that infants in Groups $\mathrm{NC} / \mathrm{C}$ and $-/ \mathrm{C}$ required reliably more training trials to complete criterion training than did adults in either group ( $\mathrm{ps}<.05$ ). No differences were observed between ages in Groups $C^{\prime} / C$, $\mathrm{R} / \mathrm{C}$, and $\mathrm{Y} / \mathrm{C}$. (Note that, since the Dunn test apportions the acceptable experimentwise error rate, .05 , equally among all comparisons, the critical range represented by our analysis represents a per comparison rate of alpha equal to .003 .)

A closer analysis of these scores indicated that $41 \%$ of the infants (pooled across treatments) erred after the first correct choice beginning the criterion run while only $33 \%$ of the adults erred $\left[\chi^{2}=12.38\right.$, $p<.02]$. Broken down by age and treatment conditions, Table 1 presents the percentage of subjects making an error after the first correct choice of the criterion run and mean number of errors committed during the criterion run. Note that the analysis of errors during the criterion run suggests that our

Table 1

Analysis of Phase 2 Learning: Percentage of Rats Making an Error During the Criterion Run (P) and Mean Number of Errors Made During the Criterion Run (E) for Infant (I) and Adult (A) Rats

\begin{tabular}{cccc}
\hline Treatment & Group & P & E \\
\hline \multirow{2}{*}{$\mathrm{C}^{\prime} / \mathrm{C}$} & $\mathrm{I}$ & .43 & 1.77 \\
& $\mathrm{~A}$ & .53 & 1.13 \\
$\mathrm{R} / \mathrm{C}$ & $\mathrm{I}$ & .20 & 1.17 \\
& $\mathrm{~A}$ & .10 & 1.33 \\
$\mathrm{Y} / \mathrm{C}$ & $\mathrm{I}$ & .50 & 1.33 \\
& $\mathrm{~A}$ & .03 & 2.00 \\
$\mathrm{NC} / \mathrm{C}$ & $\mathrm{I}$ & .37 & 1.20 \\
& $\mathrm{~A}$ & .33 & 1.20 \\
$-/ \mathrm{C}$ & $\mathrm{I}$ & .60 & 1.61 \\
& $\mathrm{~A}$ & .63 & 1.47 \\
\hline
\end{tabular}

analysis of trials to complete criterion training in Phase $\mathbf{2}$ may have underestimated the age differences in Treatment $\mathrm{Y} / \mathrm{C}$ due to a "floor" effect affecting adult performance. Such a potential measurement problem cannot, however, account for the equivalent rates of acquisition by infants and adults previously given the $C^{\prime} / C$ and $R / C$ treatments. Apparently, prior experience with both the training apparatus and the escape-response contingency were necessary for the infants to benefit from Phase 1 experience. Adults demonstrated a similar benefit from prior experience with the training apparatus (see Treatments $\mathrm{R} / \mathrm{C}$ and $\mathrm{Y} / \mathrm{C}$ ) and the escape response contingency (Treatment $R / C$ ). Finally, there were indications that the adult rats appear to have learned more than did the infants about the contingency in Phase 1 between apparatus cues and the escape response, yielding more negative transfer from this source among the adults. Compared with the infants, adults in Group $\mathrm{C}^{\prime} / \mathrm{C}$ made more errors in Phase 2 once the criterion run had begun (adults = $53 \%$, infants $=43 \%$ ), and adults made their last error later in the criterion run than infants (adults = 3.44; infants $=2.69$ ).

For Experiment 1B, a $3 \times 2 \times 2$ analysis of variance $(3$ retention intervals $\times 2$ treatment conditions $\times$ male vs. female adult rats) performed on the number of trials to complete criterion training indicated reliable main effects of treatment conditions $[F(1,36=12.36, p<.001]$ and sex $[F(1,36)$ $=4.55, \mathrm{p}<.05]$. Males learned more rapidly than did females. Because the sex factor failed to affect subsequent retention scores, however, no further mention will be made of it. The main effect of treatment conditions agrees with the findings of Experiment 1A of negative transfer in Group $C^{\prime} / C$ relative to the control treatment. On the average, rats in Group $C^{\prime} / C$ required 12.5 trials $(\mathrm{SE}=.82)$, while Group $-/ C$ rats required 9.96 trials $(\mathrm{SE}=.16)$ to complete criterion training.

Analysis of the errors committed during the criterion run produced the same statistical picture observed among adults in Experiment 1A, so further elaboration is unnecessary.

\section{Retention Test}

The test for retention in Experiment $1 \mathrm{~A}$ occurred 2 min, 1 day, or 7 days after the completion of Phase 2 training. Experiment 1B tested the retention of adult rats 1 day, 30 days, or 65 days after Phase 2 training. The results of both experiments are graphed in Figure 2. Note that the 1-day retention for adults in Treatments $C^{\prime} / C$ and $-/ C$ are pooled across Experiments $1 \mathrm{~A}$ and $1 \mathrm{~B}$. Figure 2 depicts the mean probability, for each of the 36 orthogonal groups, of performing the response alternative that had been rewarded during Phase 2 (pooled across Trials 1-10). Recall that testing consisted of 10 shock-escape trials with 
the same procedures used in Phase 2 except that the shock was terminated upon the selection of either response alternative of the T-maze. This testing procedure was selected to minimize the contribution of new learning during the retention test.

A $2 \times 5 \times 3 \times 2$ factorial analysis $(2$ ages $\times 5$ treatment conditions $\times 3$ retention intervals $\times$ male vs. female subjects) performed on the Experiment $1 \mathrm{~A}$ data represented in Figure 2 indicated four reliable interactions-age $\times$ treatment conditions $\times$ retention interval $[\mathrm{F}(8,240)=1.97, \mathrm{p}<.05]$, age $\times$ treatment conditions $[\mathrm{F}(4,240)=2.94, \mathrm{p}<.025]$, age $\times$ retention interval $[\mathrm{F}(2,240)=29.73, \mathrm{p}<.001]$, and treatment $\times$ retention interval $[F(8,240)=2.23$, $\mathrm{p}<.025]$. The analysis failed to implicate the involvement of the sex factor in any interaction or main effect, so, in Figure 2, treatment means were obtained by collapsing across sex. The basis of these interactions can be clarified by separate consideration of the infants and adults.

Infant retention. The average age of infant rats at the time of the retention test was as follows: for a 2min test, mean $=17.9$ days; for a 1 -day test, mean $=$ 18.6 days, for a 7 -day test, mean $=24.8$ days. While both infants and adults in the control treatment $(-/ \mathrm{C})$ demonstrated nearly equal retention at the 2 -min and 1-day retention tests (see Figure 2), by the 7-day retention test, infants exhibited the relatively rapid rate of forgetting characteristic of infancy (Campbell \& Spear, 1972). To evaluate proactive interference, comparisons were made between Group -/C and each of the treatment conditions. Note that, among the infants, each of Groups $C^{\prime} / C, R / C$, and $Y / C$ demonstrated more rapid forgetting than did the control treatment, Group -/C. Since all animals performed perfectly in the 2 -min retention test, it was suggestive that the initial degree of learning was equivalent among treatment conditions. By the $24-\mathrm{h}$ test, retention performance of Groups $C^{\prime} / C, R / C$, and $\mathrm{Y} / \mathrm{C}$ was observed to be slightly poorer than that for

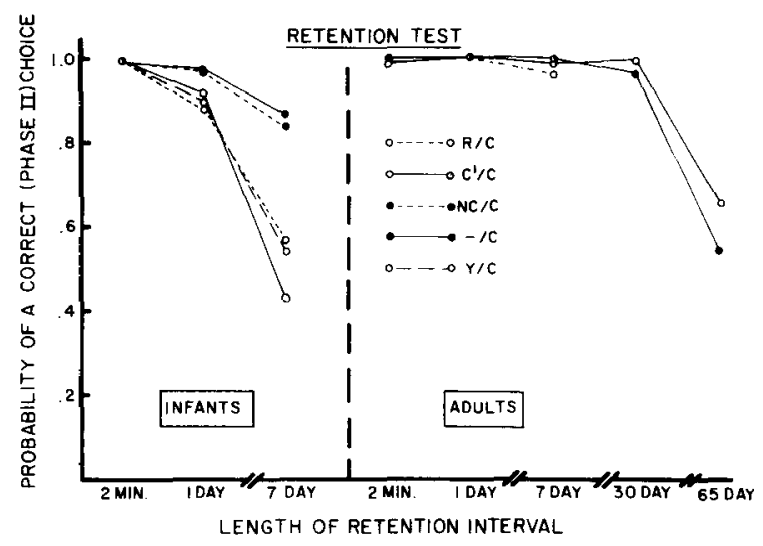

Figure 2. Testing scores: probability of selecting that choice previously correct during Phase 2 acquisition. Note that, for testing, the selection of either arm of the maze terminated footshock.
Groups $-/ \mathrm{C}$ and NC/C. By the 7th day, test performance of $C^{\prime} / C, R / C$, and $Y / C$ was at chance levels, while that of $-/ \mathrm{C}$ and $\mathrm{NC} / \mathrm{C}$ still indicated substantial retention. A separate analysis of the retention performance of the infant rats indicated the presence of a reliable treatment condition $\times$ retention interval interaction $[F(8,120)=2.13, p<.05)$. No other interactions approached statistical significance.

An analysis of the trend components of the treatment $\times$ retention interval interaction was performed on these data to examine the rates of forgetting among these younger animals. This analysis indicated that: (1) $\mathrm{C}^{\prime} / \mathrm{C}$ differed from $-/ \mathrm{C}$ and $\mathrm{NC} / \mathrm{C}$ $[\mathrm{Fs}(1,120)=11.28$ and 9.62 , respectively, ps $<.01]$; (2) $\mathrm{R} / \mathrm{C}$ differed from $-/ \mathrm{C}$ but not $\mathrm{NC} / \mathrm{C}[\mathrm{F}(1,120)$ $=4.74, \mathrm{p}<.05$, and $\mathrm{F}(1,120)=3.64, \mathrm{p}<.10$, respectively]; and (3) Y/C differed reliably from both $-/ \mathrm{C}$ and $\mathrm{NC} / \mathrm{C}[\mathrm{Fs}(1,120)=5.90$ and 4.74 , respectively, ps $<.05]$. Furthermore, neither $-/ \mathrm{C}$ nor NC/C differed statistically from one another $(F<1)$ nor did Groups $\mathrm{C}^{\prime} / \mathrm{C}, \mathrm{R} / \mathrm{C}$, and $\mathrm{Y} / \mathrm{C}$ differ statistically from each other (all ps $>.10$ ).

Overall, the results of the trend analyses indicate that Groups $C^{\prime} / C, R / C$, and $Y / C$ exhibited a faster decline in performance across retention intervals (forgetting) than did Groups $-/ \mathrm{C}$ or $\mathrm{NC} / \mathrm{C}$. Note that the behavior of Group NC/C in Experiment 1A precludes the possibility that mere noncontingent shock experience (or total shock exposure) was responsible for the treatment effects. This confirms the existence of PI in Groups $C^{\prime} / C, R / C$, and $Y / C$.

Adult retention. With regard to the adult retention performance seen in Figure 2, all groups exhibited essentially perfect retention performance at all retention intervals examined in Experiment 1A. Phase 1 experience had no measured effect on retention performance across any retention intervals examined in this experiment.

In Experiment 1B, retention performance of adult rats in Groups $C^{\prime} / C$ and $-/ C$ was examined 1 day, 30 days, and 65 days after Phase 2 learning. A $2 \times 3$ analysis of these data ( 2 treatment conditions $\times 3$ retention intervals) indicated a reliable main effect of retention interval $[F(2,42)=11.02, p<.001]$. No other main effects or interactions reached statistical significance (all Fs $<1$ ). The main effect of retention interval indicates that the spatial discrimination was forgotten across the 65-day retention interval. The absence of any kind of a statistical interaction suggests that Groups $-/ C$ and $C^{\prime} / C$ forgot the spatial discrimination at similar rates. In other words, in spite of considerable simple forgetting, PI was not found for adult rats.

In summary, long-term retention of the spatial discrimination was found to be better for adult than infant rats, but of primary interest was the finding that prior experience with certain conditions of proactive interference $\left(C^{\prime} / C, R / C\right.$, and $\left.Y / C\right)$ enhanced for- 
getting only for infant rats. This was substantiated by Experiment 1B, which determined that, while adults showed substantial forgetting of the spatial discrimination 65 days after Phase 2 learning, conditions of proactive interference found to impair infantile retention in Experiment $1 \mathrm{~A}$ did not affect forgetting in adults. From these results, it would appear difficult to escape the conclusion that PI was greater for infant than adult rats.

\section{Discussion}

The results of the present experiments provide new evidence regarding the role of proactive interference (PI) in infantile forgetting. There were three results of primary interest in these experiments: (1) While infants showed substantial forgetting of a spatial discrimination 7 days after Phase 2 training, adults required 65 days to forget the discrimination. This finding adds to previous evidence indicating the extraordinary magnitude of the forgetting that occurs for information acquired during infancy (Campbell \& Coulter, 1976; Campbell \& Spear, 1972; Spear, 1978, chap. 5). (2) Prior exposure to the training apparatus, involving either contingent or noncontingent learning experiences, exacerbated forgetting among infant but not adult rats. (3) For two of the three treatment conditions showing enhanced forgetting due to proactive interference in infant rats ( $R / C$ and $Y / C)$, positive transfer of learning occurred from Phase 1 to Phase 2. In the other treatment, $\mathrm{C}^{\prime} / \mathrm{C}$, it is likely that some components of positive transfer also occurred, in light of this group's failure to show negative transfer in a reversal situation in which negative transfer is common, and in fact occurred for adult rats in these experiments. We wish merely to call attention to this point and shall withhold speculation as to the possible theoretical significance of these relationships between transfer and forgetting.

The finding that PI was not manifested for the spatial discrimination in adult rats is consistent with a number of experiments (Crowder, 1967; Kehoe, 1963; Rickard, 1965; Zentall, 1970; also see Gleitman, 1971 , and Spear, 1971, for reviews). Worth mentioning is the experiment by Crowder (1967), which reported that, although a retention control group exhibited reliable forgetting of an appetitive spatial discrimination after 7 days, there was no evidence of PI in experimental animals. Maier and Gleitman (1967), however, suggested that the failure of animal experiments to observe PI for a spatial discrimination was because the vast majority failed to sample sufficiently long retention intervals. This interpretation may now be questioned in light of Kehoe's failure to observe PI after 30 days (Kehoe, 1963), Zentall's failure to observe PI after $\mathbf{4 0}$ days, and the failure of Experiment 1B to demonstrate PI after 65 days even though sufficient time had passed for the observation of extensive forgetting. While it is possible that, had retention been tested at an interval intermediate between 30 and 65 days, PI may have been found among adults, the consistent failure to demonstrate PI for a simple spatial discrimination in adult rats, in contrast with the present finding of three cases of PI in infant rats, lends credence to the conclusion that infant rats are more susceptible to proactive interfering events than are adults.

\section{EXPERIMENT 2}

The results of Experiment 1 indicate that immature rats are more susceptible to proactive interference in a spatial maze discrimination than are adult rats. In Experiment 2, our intentions were to assess whether a similar ontogenetic difference in the influence of proactive interference would also occur for nonspatial avoidance learning. We chose the version of avoidance learning reported previously by Spear et al. (1972) to produce substantial PI in the retention of adult and weanling rats. Spear et al. had concluded that for this task, the influence of PI was not different for the immature and mature rat. The ages of their younger animals were above those of the infants in Experiment 1, however-23-25 days old compared with 16 days old. The attempts by Spear et al. to test 16-17-day-olds on this problem had been unsuccessful; infants of this age had enough difficulty in acquiring the active avoidance to produce learning rate differences between infants and adults that were too large to permit strong inferences about the role of ontogeny in forgetting. For the present experiment, slightly older infants were selected to promote more adultlike learning, but their age (18 days old) was still younger than the ages used in Spear et al. to enhance potential age-related effects of $\mathrm{PI}$.

For the first phase of Experiment 2, half the rats at each age were given passive-shock-avoidance training (PA). During this phase, the rats learned to avoid the black compartment of an avoidance apparatus by remaining in the alternative, white compartment. The remaining half were given equivalent handling outside the avoidance apparatus. Immediately after completion of the first phase, all rats learned to enter the black compartment rapidly (within $5 \mathrm{sec}$ ) in order to avoid a footshock delivered in the white compartment (active-shock-avoidance, AA). For the retention test, rats were given a single nonshock test trial either 3 or 60 min following the completion of $\mathrm{AA}$ training. We selected these retention intervals since, unlike the spatial discrimination task, PI for the adult rat learning this avoidance task can be observed after intervals as short as 60 min (Spear et al., 1972; Spear, Smith, Bryan, Gordon, Timmons, \& Chiszar, 1980). Furthermore, the selection of these intervals sought to minimize those performance deficits com- 
monly observed after intermediate intervals (i.e., the Kamin effect) that could only act against the detection of PI.

The single test trial was conducted exactly as those of passive and active avoidance training but with neither response-shock contingency. If retention of active avoidance were subject to proactive interference from prior passive avoidance, rats should demonstrate progressively slower crossover latencies, relative to controls that had not learned passive avoidance, as the retention interval lengthens (Spear et al., 1972).

The choice of a single test proved significant since (1) the Kamin effect does not appear to be observed after only one test trial (Kamin, 1963), and (2) PI is rarely observed for avoidance learning when retention performance has been examined beyond the first test trial because the subsequent trials act to reinstate or reactivate performance (see Spear, 1971).

\section{Method}

\section{Subjects}

Ninety-six albino Sprague-Dawley rats, born and reared in the colony at the State University of New York, were used in this experiment. These rats were distributed equally between two age groups: 48 18-19-day-old infants and 48 80-day-old adults. Within each of the two age groups, rats were assigned quasi-randomly, 24 per group (12 males and 12 females), into two treatment conditions. Housing and maintenance were identical to those of Experiment 1 .

\section{Apparatus}

The apparatus was an avoidance apparatus consisting of two adjacent compartments, one white and the other black. Each compartment $(26.5 \mathrm{~cm}$ long $\times 14.5 \mathrm{~cm}$ high $\times 12.5 \mathrm{~cm}$ wide) rested on a grid-floor section capable of being independently electrified by a Grason-Stadler shock generator and scrambler (Model E 1065 GS). Separating the compartments was an opaque door which, when lowered, formed a hurdle $(2.5 \mathrm{~cm}$ for adults, $.5 \mathrm{~cm}$ for infants) and initiated a 2-cps flashing 7.5-W incandescent light and a latency timer.

\section{Phase 1 Training}

In Phase 1 , half the rats received passive avoidance training (PA-AA), while the other half received an equivalent amount of handling (-AA). For passive avoidance training, the rat was first placed in the white compartment of the apparatus facing away from the door. Approximately $3 \mathrm{sec}$ later, the door was lowered and the rat was allowed access to the black compartment. Upon crossing over into the black compartment, the rat received a 3-sec 1.6-mA inescapable footshock through the grid floor. The rat was then removed from the black compartment and was placed in a holding cage for $30 \mathrm{sec}$ (ITI) to await the next training trial. If, on the subsequent trials, the rat failed to cross over into the black compartment within $60 \mathrm{sec}$, an avoidance was counted and the rat was returned to the holding cage. Training continued until the rat successfully withheld crossing into the black compartment for $60 \mathrm{sec}$ on two consecutive trials, after which 10 additional trials of this kind were given.

\section{Phase 2 Training}

Thirty seconds after the completion of Phase 1, all rats were given active avoidance training (AA). AA was identical to PA except, of course, for the response-footshock contingencies. The rat was first placed in the white compartment of the apparatus facing away from the door. When the door was lowered, the rat avoided footshock if it stepped across into the black compartment within $5 \mathrm{sec}$. A failure to step across into the black compartment within $5 \mathrm{sec}$ initiated a $1.6-\mathrm{mA}$ footshock delivered through the grid floor in the white compartment. The shock remained on until the rat escaped to the black compartment.

After crossing into the black compartment, the rat was removed immediately and placed in the holding cage for the IT1. Training on AA continued until the rat successfully avoided the footshock on three consecutive trials.

Immediately after attaining the AA criterion, all rats were returned to their homecages until the retention test.

\section{Testing}

The retention test occurred either 3 or $60 \mathrm{~min}$ after the completion of Phase 2 training. The test trial was identical to the training trials given during Phases 1 and 2 except that no shocks were administered in either compartment. The rat was placed into the white compartment, facing away from the door, and, after lowering the door, latency to crossover into the black compartment was recorded.

\section{Design}

This experiment employed a $2 \times 2 \times 2$ factorial design ( 2 ages $\times 2$ treatment conditions $\times 2$ retention intervals) with 12 rats (6 males and 6 females) assigned to each of the 8 orthogonal treatment groups. The data obtained were analyzed with an analysis of variance test, with appropriate planned comparisons.

\section{Results}

\section{Acquisition}

During Phase 1 PA training, infants required, on the average, 14.0 trials $(\mathrm{SE}=.22)$ to complete the training criterion, compared with 13.4 trials $(\mathrm{SE}=$ .13) for the adults. Analysis of these data indicated a reliable main effect of age $[F(1,44)=5.80, p<$ $.025]$. The factor of subsequent retention interval neither interacted with age nor contributed to a main effect $(F<1)$.

Analysis of Phase 2 AA training indicated a main effect of age on rate at which the AA was acquired $[F(1,88)=11.23, p<.01]$. Irrespective of training treatment, infants (PA-AA: 13.5, $\mathrm{SE}=1.4$; $-\mathrm{AA}$ : 11.6, $\mathrm{SE}=1.1$ ) required more training trials to acquire the AA than did adults (PA-AA: 9.3, SE = 1.1 ; -AA: $8.5, \mathrm{SE}=.66$ ). No other main effects or interactions attained statistical significance (all ps $>$ $.10)$.

As expected, an analysis of the mean crossover latency on the last $A A$ training trial indicated that adult rats (PA-AA: $1.45 \mathrm{sec}, \mathrm{SE}=.33 ;-\mathrm{AA}: 1.80 \mathrm{sec}$, $\mathrm{SE}=.27$ ) traversed the distance between the white and black compartments faster than did infant rats (PA-AA: $3.57 \mathrm{sec}, \mathrm{SE}=.14$; $-\mathrm{AA}: 3.10 \mathrm{sec}, \mathrm{SE}=.20$ ). The difference was reliable $[F(1,80)=56.82, p<.001]$.

Curiously, the analysis indicated the age $x$ treatment condition interaction was marginally significant $[F(1,88)=3.33, p<.07]$, reflecting that the infants in Group PA-AA had longer crossover latencies than did age-mates in Group -AA, while a slight trend in the opposite direction was evident for the adult treatment groups. This interaction suggests that 
negative transfer from Phase 1 PA training tended to persist longer into Phase 2 AA training for infants than for adults.

\section{Test}

The mean crossover latency scores for each treatment at each retention interval are shown in Figure 3. As infants and adults differed in terms of latency on the last AA training trial, an analysis of covariance was conducted to correct latency scores on the test in terms of terminal training latencies. After preliminary tests determined that our treatment populations met the assumptions inherent in the analysis of covariance (see Keppel, 1973, pp. 438-484), a $2 \times$ $2 \times 2$ analysis of covariance $(2$ ages $\times 2$ treatment conditions $\times 2$ treatment intervals) was performed on the test trial latency scores. Between-age analyses indicated a reliable age $\times$ retention interval interaction $[F(1,85)=5.57, p=.02]$. At the 3-min test, infants tended to cross into the black compartment more slowly than did the adults, while at the 60-min test, adults crossed more slowly than did infants.

A separate within-age analysis indicated that, for infants, there was a reliable main effect of treatment condition $[F(1,44)=11.33, p<.01]$, which did not interact with retention interval $(F<1)$. This main effect indicates that infants in Group PA-AA crossed more slowly into the black compartment than their age-mates in Group - $\mathrm{AA}$, irrespective of retention interval. As infants in Group PA-AA demonstrated slower crossover latencies than age-mates in Group -AA on the test but not at the end of training, PI after even the shorter retention interval is indicated for infants.

For adults, on the other hand, only a main effect of retention interval $[F(1,44)=17.75, p<.001]$ was significant; this effect marginally interacted with that of the PI treatment condition $[F(1,44)=3.37, p=$

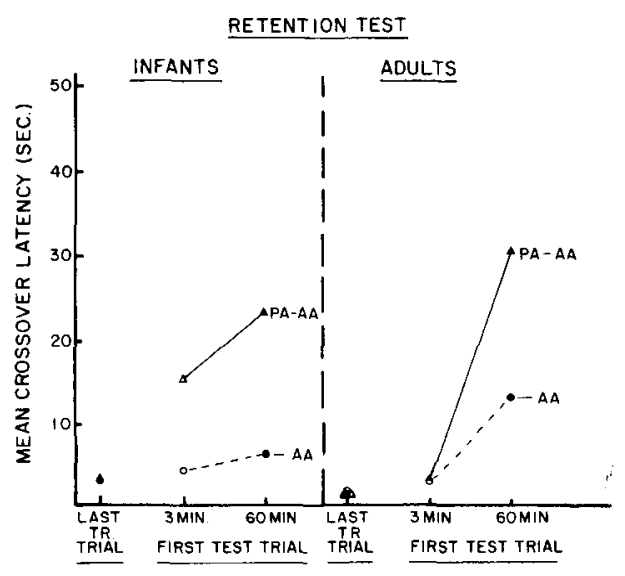

Figure 3. Testing latency: mean crossover latencies for infant and adult rats on the last Phase 2 training trial and for test trials either 3 or 60 min later. (Experiment 2)
.07]. The main effect of treatment condition also was marginally significant $[F(1,44)=3.83, p=.06]$. The finding of a slight but not statistically robust PI effect among the adult animals under these conditions is consistent with the findings of others at these retention intervals (Gordon \& Spear, 1973; Spear et al., 1972). Consistent with Spear et al. (1980), the results observed for adults suggest that the cues for the most recently acquired memory may momentarily inflate the probability of retrieving the target attribute of the AA memory. This momentary enhancement of retrieving the AA memory, however, is transient, and as the interval between AA training and testing increases, the more likely it is that the memory of prior PA training will intrude and interfere with the retrieval of the AA memory.

\section{Discussion}

The results of the present experiment indicate that the relative susceptibility of immature and mature animals to sources of proactive interference may depend on the specific task requirements. This interpretation agrees with a similar interpretation of infantile forgetting mechanisms advanced by Haroutunian and Campbell (in press) in suggesting that processes responsible for the exaggerated forgetting in infancy are task specific. It is also in concurrence with earlier suggestions that the mechanisms of proactive interference may differ for the discrimination task of Experiment 1 and the go/no-go task of Experiment 2 (Spear, 1971). But, in spite of these task differences, it would be unwise to ignore the similar trends in both of the present experiments toward greater interaction between conflicting memories among infants than among adults. Although not confirmed by a statistically significant three-way interaction (age $x$ treatment condition $\times$ retention interval), the results of Experiment 2 suggested that infants suffer PI over short intervals, whereas adult organisms do not.

It is significant to note that our attempts to minimize performance factors appear to have been successful. Even though it is still possible that at each age retention performance after 60 min may have been confounded by the "Kamin effect," it is unlikely that this could have contributed to the enhanced PI observed among infants, but not adults, after the 3-min retention interval. Similarly, if "warm-up" decrements in performance are viewed as motor warm-up, it would be difficult to envision why motor deficits would be greater for rats in Group PA-AA than in Group -AA. On the other hand, if warm-up decrements are viewed as a memory retrieval failure (Spear, Gordon, \& Martin, 1972), it is possible that retention performance in the present experiment reflects both the combined influence of PI and warmup decrements-in which case this would be quite compatible with our orientation. 


\section{GENERAL DISCUSSION}

The results of the present series of experiments support an interpretation that allows for a central role of psychological (experiential) factors in explaining infantile forgetting patterns. Of primary importance are these present findings: (1) While infants demonstrated substantial forgetting of a spatial discrimination 7 days after training, adults required nearly 65 days to achieve a similar loss in retention. (2) In terms of spatial discrimination, proactive interference (PI) increased forgetting for infants but not for adults. (3) In terms of a go/no-go avoidance task in which the spatial dimension seems relatively unimportant, the age-dependent effect of PI was not seen so clearly. There was an indication that PI impaired retention across short intervals for infants when no PI was evident for adults. However, the effect was not robust enough to support an unequivocal statement that the specific source of interference affected infants more than it did adults. This leads to the possibility that the weight of particular sources of forgetting affecting the immature organism may depend upon what is learned (see, also, Haroutunian \& Campbell, in press, Spear, 1979).

One conventional view of $\mathrm{PI}$ is in terms of response competition. Two or more responses common to a stimulus are said to compete for expression during the retrieval process. This interpretation, however, has difficulty in explaining the persistent finding that adults do not exhibit PI in a spatial orientation task (e.g., Experiment 1) even though Phase 1 and 2 training meets all the requirements necessary for demonstrating response competition. Similarly, it is difficult to explain why infants merely exposed to the apparatus cues, independently of an explicit response contingency (Group Y/C), should be subject to such "response competition" when control rats (Group $\mathrm{NC} / \mathrm{C}$ ) receiving identical treatment in a totally different apparatus are not.

Among a variety of alternative views of PI, we find particularly appealing the suggestion of Hasher and Johnson (1975) that a modification in acquisition processes during Phase 2 , caused by Phase 1 , leads to PI. These authors have suggested that PI results whenever the organism uses a less efficient learning strategy in acquiring Task 2 than would have been used had Task 1 been omitted. If we assume that adults are more effective than infants in elaborating information (i.e., bringing together information), then adults may be able to avoid PI under certain circumstances by more efficiently comparing, contrasting, and hence segregating Phase 1 and Phase 2. The exacerbation of forgetting observed among infants presented a source of interference (Phase 1) may result from a special disposition of these young organisms in "selecting" what is to be learned during Phase 2, which failed to provide the breadth of information necessary to increase the discriminability of Phase 2 from Phase 1. This view would also account for infants in Group $\mathrm{C}^{\prime} / \mathrm{C}$ having no negative transfer under conditions suitable for producing it among adults.

Another alternative worth mentioning has recently been suggested by Wickens, Tuber, and Wickens (Note 2). These authors have suggested a number of principles that require representation here due to their special relevance to the present data (see, also, Wickens, Tuber, Nield, \& Wickens, 1977): (1) If stimuli occur repeatedly in isolation and in a random fashion, an attitude of indifference will develop. (2) The attitude of indifference will become attached to the contextual cues of the training environment. (3) Given a predictable relationship between stimuli, an associative relationship can be established, and the acquired indifference will be suppressed. (4) Other things being equal, initial experiences with stimuli establish a priority over subsequent contrary learning, and, although they may be suppressed (see Principle 3) during contrary experiences, they will tend to gain dominance across time (Wickens et al., Note 2).

These principles address in particular the following results from the present Experiments 1 and 2: (1) Only infants in Groups $\mathrm{C}^{\prime} / \mathrm{C}$ and PA-AA (reversal training/ trained), $\mathrm{R} / \mathrm{C}$ (noncontingent stimulus exposure/ trained), and $\mathrm{Y} / \mathrm{C}$ (noncontingent stimulus and response exposure/trained) demonstrated reliable $\mathrm{PI}$. (2) Group NC/C (noncontingent shock exposure/ trained), which received the noncontingent exposure in a different context from Groups $C^{\prime} / C, R / C$, and $\mathrm{Y} / \mathrm{C}$, failed to exhibit PI. From the perspective suggested by Wickens et al. (Note 2), the behavior of Groups $C^{\prime} / C$ and PA-AA could be explained by Principles 3 and 4, Groups $R / C$ and $Y / C$ could be explained by Principles 1, 3, and 4, and Group NC/C could be explained by Principle 2 . However, in order to explain why adults exhibit less PI than do infants under similar experimental conditions, it is necessary to assume that infants learn more about the initial experience than do adults or that they learn something different from what adults learn. Some recent evidence supports this possibility (Spear, 1979; Solheim, Hensler, \& Spear, Note 3).

In conclusion, the present series of results indicates that, under certain circumstances, information acquired just prior to a second target memory may be more detrimental for infants than for adults as a source of proactive interference that enhances forgetting of the target memory.

\section{REFERENCE NOTES}

1. Berk, A. M., Vigorito, M., \& Miller, R. R. A latent extinction model of infantile amnesia in rats. Unpublished manuscript, 1979.

2. Wickens, C. D., Tuber, D. S., \& Wickens, D. D. Prior noncontingent experience and memory for a CR: Data and theory. Paper presented at the meeting of the Psychonomic Society, 1979 (expanded manuscript received from D. D. Wickens, June 1980).

3. Solheim, G., Hensler, J., \& Spear, N. E. Age-dependent 
contextual effects on short-term active avoidance retention in rats. Unpublished manuscript, presented at the meeting of the Eastern Psychological Association, 1980.

\section{REFERENCES}

Allport, G. W. Personality: A psychological interpretation. New York: Holt, 1937.

Campbell, B. A., \& Coulter, X. Ontogeny of learning and memory. In M. R. Rosenzweig (Ed.), Neural mechanisms of learning and memory. Cambridge, Mass: M.I.T. Press, 1976.

Campbell, B. A., Misanin, J. R., White, B. C., \& Lytle, L. D. Species differences in ontogeny of memory: Indirect support for neural maturation as a determinant of forgetting. Journal of Comparative and Physiological Psychology, 1974, 87, 193-202.

Campbell, B. A., \& Spear, N. E. Ontogeny of memory. Psychological Review, 1972, 79, 215-236.

Crowder, R. G. Proactive and retroactive inhibition in the retention of a T-maze habit in rats. Journal of Experimental Psychology, 1967, 74, 167-171.

Freud, S. A general introduction to psychoanalysis. New York: Clarion Books, 1935.

Gleitman, H. Forgetting of long-term memories in animals. In W. K. Honig \& P. H. R. James (Eds.), Animal memory. New York: Academic Press, 1971.

Gordon, W. C., \& Spear, N. E. Effect of reactivation of a previously acquired memory on the interaction between memories in the rat. Journal of Experimental Psychology, 1973, 99, 349-355.

Haroutunian, V., \& Campbell, B. A. Maturational changes in learning and memory in selected altricial species. In J. L. McGaugh \& R. F. Thompson (Eds.), Neurobiology of learning and memory. New York: Plenum Press, in press.

HAsher, L., \& Johnson, M. K. Interpretive factors in forgetting. Journal of Experimental Psychology: Human Learning and Memory, 1975, 1, 567-575.

Kall, R. V., \& Schroll, J. T. Evaluation and taxonomic encoding in children's memory. Journal of Experimental Child Psychology, 1974, 18, 426-437.

KAMIN, L. J. Retention of an incompletely learned avoidance response: Some further analyses. Journal of Comparative and Physiological Psychology, 1963, 56, 713-718.

KеноE, J. Effects of prior and interpolated learning on retention in pigeons. Journal of Experimental Psychology, 1963, 65, 537545.

KEPPEL, G. Design and analysis: $A$ researcher's handbook. Englewood Cliffs, N.J: Prentice-Hall, 1973.
Maier, S., \& Gleitman, H. Proactive interference in rats. Psychonomic Science, 1967, 7, 25-26.

Perkins, C. C., JR. A conceptual scheme for studies of stimulus generalization. In D. I. Mostofsky (Ed.), Stimulus generalization. Stanford, Calif: Stanford University Press, 1965.

ReIfF, R., \& Scheerer, M. Memory and hypnotic age regression: Developmental aspects of cognitive function explored through hypnosis. New York: International Universities Press, 1959.

RICKard, S. Proactive inhibition involving maze habits. Psychonomic Science, 1965, 3, 401-402.

Sмiтh, N. Effects of interpolated learning on the retention of an escape response in rats as a function of age. Journal of Comparative and Physiological Psychology, 1968, 65, 422-426.

SpE AR, N. E. Forgetting as retrieval failure. In W. K. Honig \& P. H. R. James (Eds.), Animal memory. New York: Academic Press, 1971.

SPEAR, N. E. The processing of memories: Forgetting and retention. Hillsdale, N.J: Erlbaum, 1978.

Spear, N. E. Memory storage factors leading to infantile amnesia. In G. Bower (Ed.), The psychology of learning and motivation (Vol. 13). New York: Academic Press, 1979.

Spear, N. E., Gordon, W. C., \& Chiszar, D. A. Interaction between memories in the rat: Effect of degree of prior conflicting learning on forgetting after short intervals. Journal of Comparative and Physiological Psychology, 1972, 78, 471-477.

Spear, N. E., Gordon, W. C., \& Martin, P. A. Warm-up decrement as failure in memory retrieval in the rat. Journal of Comparative and Physiological Psychology, 1973, 85, 601-614.

Spear, N. E., Smith, G. J., Bryan, R., Gordon, W., Timmons, R., \& Chiszar, D. Contextual influences on the interaction between conflicting memories in the rat. Animal Learning \& Behavior, 1980, 8, 273-281.

Underwood, B. J., \& Ekstrand, R. B. An analysis of some shortcomings in the interference theory of forgetting. Psychological Review, 1966, 73, 540-549.

Vandament, W., Burright, R. G., Fessenden, R. R., \& BARKER, W. H. Tables of event sequences for sequential analyses of data in psychological experiments containing two-class events. Behavioral Research Methods \& Instrumentation, 1970, 2, 290-296.

Wickens, D. D., Tuber, D. S., Nield, A. F., \& Wickens, C. Memory for the conditioned response: The effects of potential interference introduced before and after original conditioning. Journal of Experimental Psychology: General, 1977, 106, 47-70.

Zentall, T. R. Effects of context change on forgetting in rats. Journal of Experimental Psychology, 1970, 86, 440-448.

(Manuscript received July 22, 1980; revision accepted for publication February 10, 1981.) 